\title{
Fitotoxicidade da fase orgânica e do composto majoritário obtidos da polpa dos frutos de Crescentia cujete L. (Bignoniaceae)
}

\author{
Sinval Garcia Pereira ${ }^{1 *}$ \\ Giselle Maria Skelding Pinheiro Guilhon ${ }^{2}$ \\ Lourivaldo da Silva Santos ${ }^{2}$ \\ Luidi Cardoso Pacheco ${ }^{2}$ \\ Antônio José Cantanhede Filho ${ }^{2}$ \\ Antônio Pedro da Silva Souza Filho ${ }^{3}$ \\ ${ }^{1}$ Universidade Federal do Maranhão, Centro de Ciências Agrárias e Ambientais \\ Coordenação de Ciências Biológicas, Campus IV \\ BR 222, km 04, Bairro Boa Vista, CEP 65.000-000, Chapadinha - MA, Brasil \\ ${ }^{2}$ Universidade Federal do Pará, Programa de Pós-Graduação em Química \\ Instituto de Ciências Exatas e Naturais, Campus Universitário do Guamá - Campus Básico \\ Rua Augusto Corrêa, 1, CEP 66075-110, Belém do Pará - PA, Brasil \\ ${ }^{3}$ EMBRAPA Amazônia Oriental, Laboratório de Agroindústria \\ Travessa Dr. Enéas Pinheiro, s/n, Caixa Postal, 48, CEP 66095-100, Belém, PA - Brasil \\ * Autor para correspondência \\ sinval@ufma.br \\ sinval.garcia@bol.com.br
}

Submetido em 01/04/2015

Aceito para publicação em 08/09/2015

\section{Resumo}

Avaliou-se a fitotoxicidade do extrato etanólico (CETOH), da fase orgânica (CEA) e do composto majoritário, o ácido (E)-cinâmico (AC), obtidos da polpa dos frutos da espécie popularmente conhecida como cujuba, cuieira e/ou cabaça (Crescentia cujete L.) sobre a inibição da germinação de sementes, desenvolvimento do hipocótilo e radícula das plantas invasoras Senna obtusifolia (L.) Irwin \& Barneby (mata-pasto) e Mimosa pudica Mill. (malícia). A fase orgânica na concentração de $0,5 \%$ inibiu em $100 \%$ a germinação das sementes das duas plantas invasoras. O AC que foi obtido da fase orgânica inibiu a germinação das sementes de S. obtusifolia em $95 \%$ e de $M$. pudica em $99 \%$ na concentração de $0,1 \%$, com concentração (\%) tóxica para inibição de $50 \%$ $\left(\mathrm{CI}_{50}\right)$ da germinação das sementes iguais a 0,063 e $0,037 \%$, respectivamente; e nos bioensaios de crescimento de plântula, o AC foi mais eficiente sobre a radícula da planta $S$. obtusifolia (com $\mathrm{CI}_{50}$ igual a $0,009 \%$ ) e para a planta $M$. pudica os valores de $\mathrm{CI}_{50}$ foram de $0,097 \%$ e $0,117 \%$ para a radícula e hipocótilo, respectivamente. Essa pesquisa reforça o potencial fitotóxico do ácido (E)-cinâmico, verificado inicialmente na fase orgânica em acetato de etila (CEA) rica nesse fenilpropanoide.

Palavras-chave: Ácido (E)-cinâmico; Extrato etanólico; Germinação de sementes

\section{Abstract}

Phytotoxicity of the organic phase and major compound obtained from the fruit pulp of Crescentia cujete L. (Bignoniaceae). The phytotoxity of ethanol extracts, of the organic phase and major compound (cinnamic acid) 
obtained from the fruit pulp of Crescentia cujete L., were evaluated for their potential to inhibit seed germination, hypocotyl development and radicle development of the invasive weeds Senna obtusifolia (L.) Irwin \& Barneby and Mimosa pudica Mill. The organic phase at a concentration of $0.5 \%$ inhibited $100 \%$ seed germination of both weeds. Cinnamic acid obtained from the organic phase inhibited seed germination by $95 \%$ for S. obtusifolia and $99 \%$ for M. pudica at a concentration of $0.1 \%$, with concentrations (\%) inhibiting $50 \%\left(\mathrm{IC}_{50}\right)$ seed germination equal to $0.063 \%$ and $0.037 \%$, respectively. For the seedling growth bioassays, the toxicity of the cinnamic acid was more efficient for the $S$. obtusifolia radicle $\left(\mathrm{IC}_{50}\right.$ equal to $0.009 \%$ ), and for $M$. pudica the $\mathrm{IC}_{50}$ values were $0.097 \%$ and $0.117 \%$ for the radicle and hypocotyl, respectively. This research reinforces the phytotoxic potential of cinnamic acid, verified initially in the organic phase (in ethyl acetate), which is rich in this phenylpropanoid.

Key words: Cinnamic acid; Ethanol extract; Seed germination

\section{Introdução}

A espécie Crescentia cujete L. é originária da América Central. No Brasil, ocorre desde a Amazônia até a região sudeste, onde foi introduzida para cultivo. Tem fruto globoso, com até $25 \mathrm{~cm}$ de diâmetro, com epicarpo verde, flexível e, endocarpo lenhoso e resistente. A polpa, quando verde, é corrosiva e usada no tratamento de doenças respiratórias, e quando madura, é abortiva. De seus frutos também se pode obter tinturas, além de cuias, muito usadas como vasilhas (SOUZA; LORENZI, 2005).

Estudo com os frutos de C. cujete levou a obtenção principalmente de iridoides (KANEKO et al., 1997), classe de compostos tidos como marcadores taxonômico da família Bignoniaceae. Em 1998, foram isolados o acantosideo $\mathrm{D}$, benzoato de $\beta$-D-glicopiranosil, (R)-1-O- $\beta$ D-glicopiranosil-1,3-octanodiol e $\beta$-D-frutofuranosil-6-O( $p$-hidroxibenzoil)- $\alpha$-D-glicopiranosideo (KANEKO et al., 1998), furanonaftoquinonas (HELTZEL et al., 1993) e mais recentemente quatro novos iridoides (WANG et al., 2010).

Os metabólitos secundários de plantas com possíveis atividades herbicidas são investigados na busca por resolver problemas em relação aos produtos comerciais vigentes, entre eles, a resistência desenvolvida pelos organismos alvos. No manejo de plantas daninhas se procuram soluções biológicas para minimizar os impactos ambientais relacionados ao uso de herbicidas em sistemas agrícolas (TESIO et al., 2011).

A coevolução das plantas e de seus inimigos potenciais como os insetos fitófagos, microorganismos, herbívoros e mesmo outras plantas levam à produção de substâncias químicas de defesa, estratégias adaptativas para toxinas alelopáticas, aspectos atualmente importantes na investigação e busca por novos metabólitos secundários com atividade fitotóxica (MACÍAS et al., 2007).

Estudo realizado por Novaes et al. (2013) demonstrou que os efeitos do extrato aquoso de folhas de Rapanea umbellata em concentrações de $10 \%$ e $5 \%$ foi comparado com o controle (água destilada) e o herbicida sintético oxifluorfeno sobre três plantas daninhas. O estudo concluiu que o herbicida teve efeitos mais significativos do que o extrato sobre o crescimento inicial da parte aérea. No entanto, o crescimento inicial da raiz foi significativamente mais afetado pelo extrato e também causou transtornos na anatomia radicular da raiz, indicando que deve ser bioprospectada e os seus aleloquímicos purificados para a descoberta de herbicidas de origem natural.

Há vinte anos não são lançados herbicidas com novos modos de ação, contudo, o desenvolvimento de novos produtos é extremamente necessário, devido ao rápido desenvolvimento da resistência aos herbicidas comerciais e o desafio da agricultura orgânica de trabalhar com a falta de produtos naturais eficazes (DAYAN; DUKE, 2014). Além disso, os bioensaios alelopáticos contribuem para proporcionar ao pequeno produtor a mudança na sua maneira de se relacionar com a terra e diminuir ou até mesmo abolir o uso de defensivos químicos em suas propriedades (SILVA, 2012).

Dentro desse contexto, realizou-se, além do estudo químico da polpa dos frutos da espécie $C$. cujete, a investigação da ação fitotóxica do extrato, da fase orgânica e do composto majoritário, sobre a germinação de sementes, crescimento do hipocótilo e radícula das plantas invasoras conhecidas como mata-pasto [Senna obtusifolia (L.) Irwin \& Barneby] e malícia (Mimosa pudica Mill.). 


\section{Material e Métodos}

\section{Material vegetal}

Os frutos da espécie Crescentia cujete L. foram coletados na zona urbana do município de Anapurus - MA, localizado no leste maranhense, na Região do Baixo Parnaíba. A identificação foi por comparação com a exsicata MG 101788, de domínio do Herbário do Museu Paraense Emílio Goeldi em Belém - PA(MPEG).

\section{Obtenções do extrato, fase e do constituinte químico}

A polpa (3.455 g) de sete frutos recém-coletados da espécie $C$. cujete foi triturada em liquidificador juntamente com etanol na proporção de 1:2, em seguida deixou-se a mistura resultante em maceração por dez dias. Após este período filtrou-se, obtendo-se o resíduo e a solução alcoólica que foi concentrada em evaporador rotativo à pressão reduzida, obtendo-se o extrato etanólico bruto (CETOH, 300 g). O extrato bruto, após diluição em água destilada foi submetido à partição com acetato de etila, obtendo-se a fase aquosa e a fase orgânica. A fase orgânica em acetato de etila foi concentrada em evaporador rotativo a pressão reduzida, obtendo-se a fase denominada CEA (25 g), a fase aquosa foi descartada. A fase CEA (17,59 g) foi submetida à cromatografia em coluna (CC), resultando em 41 frações as quais foram monitoradas por cromatografia em camada delgada (CCD). Das frações de 7-14 foi isolado o ácido (E)-cinâmico (3,35 g) na forma de cristais em agulhas.

\section{Procedimentos gerais}

$\mathrm{Na}$ análise em Cromatografia Gasosa acoplada ao Espectrômetro de Massas (CG-EM), utilizou-se equipamento SHIMADZU 14B/QP5050A (Central Analítica do IQ-USP) com analisador tipo quadrupolo, em coluna BPX5 (não polar com 5\% de fenil polisilfenileno siloxano) de $30 \mathrm{~m}$ de comprimento e $0,25 \mathrm{~mm}$ de diâmetro. A pressão da coluna foi de $150 \mathrm{kPa}$ com vazão de $2,7 \mathrm{~mL} \mathrm{~min}^{-1}$. A temperatura inicial foi de $50{ }^{\circ} \mathrm{C}$ com temperatura final de $400{ }^{\circ} \mathrm{C}$ por temperatura do gás de $280{ }^{\circ} \mathrm{C}$ por interface também de $280{ }^{\circ} \mathrm{C}$ e o volume injetado foi de $2 \mu \mathrm{L}$ em clorofórmio.
No fracionamento por cromatografia em coluna (CC) da CEA, utilizou-se sílica gel 0,063-0,2 mm (Vetec) como fase estacionária em coluna de vidro e sistema eluente, iniciando com hexano $100 \%$ seguido de mistura de hexano-acetato de etila com aumento da polaridade em escala de 5\%, até chegar ao acetato de etila $100 \%$ e, posteriormente a mistura acetato de etila/ metanol, também com aumento de polaridade em escala de $5 \%$ e por último com metanol $100 \%$. O constituinte majoritário, o ácido (E)-cinâmico foi obtido puro e confirmado pela análise e comparação dos dados de RMN experimental com os dados da literatura (XIA et al., 2010; GOUVEIA, 2012).

A cromatografia em camada delgada comparativa (CCD) foi empregada para análise e reunião das frações obtidas por cromatografia em coluna, preparadas por uma suspensão de $30 \mathrm{~g}$ de sílica gel (60G-MERCK) com indicador de fluorescência com $60 \mathrm{~mL}$ de água destilada. As revelações das cromatoplacas foram feitas por câmara de análise de fluorescência por luz ultravioleta, cabine tipo SPECTROLINE (modelo CM10. Luz tipo SPECTROLINE modelo ENF-260C) através da exposição destas à radiação ultravioleta (UV) nos comprimentos de onda 254 e $366 \mathrm{~nm}$ e por borrifamento com solução ácida de sulfato cérico $\left(\mathrm{CeSO}_{4}\right) \mathrm{em}$ ácido sulfúrico $\left(\mathrm{H}_{2} \mathrm{SO}_{4}\right)$ /água 1:1 ou solução de $\mathrm{H}_{2} \mathrm{SO}_{4} / \mathrm{MeOH}$ 1:1, seguido de aquecimento em estufa até revelação das mesmas, e o critério de pureza adotado para as substâncias isoladas foi à observação de uma única mancha em CCD.

\section{Metodologia dos bioensaios}

Os bioensaios de potencial fitotóxico foram realizados de acordo com metodologias desenvolvidas por Inderjit e Dakshini (1995), Macías et al. (2000) e Brasil (2009).

\section{Germinação}

Foi utilizada câmara de germinação BOD, com temperatura constante de $25{ }^{\circ} \mathrm{C}$ e fotoperíodo de 12 horas. Cada placa de Petri de 9,0 cm de diâmetro, forrada com papel de filtro qualitativo, recebeu $3 \mathrm{~mL}$ da solução do extrato da fase e do ácido (E)-cinâmico, em triplicata. Após evaporação do solvente o papel de filtro 
foi umedecido com uma solução aquosa de fungicida (micostatim - 1\%), em seguida foram colocadas 20 sementes das plantas receptoras $S$. obtusifolia e M. pudica. As testemunhas receberam apenas a solução aquosa de fungicida. Foi considerada semente germinada aquela que apresentava extensão radicular igual ou superior a 2,0 mm. A germinação das sementes foi monitorada em períodos de 4 dias, sendo que 24 horas após a montagem do experimento foi realizada a primeira contagem de germinação e com contagens diárias e eliminação das sementes germinadas. Para o cálculo do percentual de inibição utilizou-se a Equação 1 (INDERJT; DAKSHINI, 1995; SANTOS et al., 2007).

Equação 1: Cálculo do percentual de inibição de germinação de sementes.

$$
\mathrm{I}(\%)=\left[1-\left(\mathrm{SG}_{\text {amostra }}\right)\right] \times 100 / \mathrm{SG}_{\text {controle }}
$$

Onde: $\mathrm{SG}_{\text {amostra }}$ - Número de sementes germinadas;

$\mathrm{SG}_{\text {controle }}$ - Número de sementes germinadas na amostra controle.

\section{Desenvolvimento da radícula e do hipocótilo das plantas testes}

A avaliação do crescimento de plântulas foi desenvolvida de acordo com as condições citadas acima para a germinação de sementes. Para cada concentração foram colocadas seis sementes pré-germinadas de $S$. obtusifolia e M. pudica, com três dias de germinação. Ao final do período de 10 dias de crescimento, mediu-se o comprimento da radícula e do hipocótilo. Para o cálculo do percentual de crescimento utilizou-se a Equação 2 (WANG, 1997; SANTOS et al., 2007).

Equação 2: Cálculo da inibição do crescimento das plântulas.

$$
\mathrm{I}(\%)=\left[1-\left(\mathrm{CEC}_{\text {amostra }}\right)\right] \times 100 / \mathrm{CEC}_{\text {controle }}
$$

Onde: $\mathrm{CEC}_{\mathrm{amostra}}-$ comprimento $(\mathrm{cm})$ da radícula ou do hipocótilo; $\mathrm{CEC}_{\text {controle }}$ - comprimento $(\mathrm{cm})$ da radícula ou do hipocótilo na amostra controle.

\section{Análise estatística}

O delineamento experimental foi inteiramente casualizado, com três repetições, para verificação dos efeitos biológicos. Aplicou-se Análise de Variância (ANOVA) e quando os efeitos de tratamentos apresentaram diferença significativa $(\mathrm{P}<0,05)$, as médias foram comparadas por meio do teste de Tukey, fixando um nível de significância de 5\%. Utilizou-se regressão linear simples (softwares SPSS 15.0; BioEstat 4.0). Os gráficos e os valores de $\mathrm{CI}_{50}$ e seus respectivos limite de confiança $95 \%\left(\mathrm{LC}_{95 \%}\right)$ foram elaborados utilizando-se o software Prism Graph Pad 6.

\section{Resultados}

A massa de 17,6 $\mathrm{g}$ fase orgânica foi submetida à separação em cromatografia em coluna (CC) e obtevese 41 frações, das frações de 7 a 14 obteve-se 3,35 g de ácido (E)-cinâmico. Nos testes de fitotoxicidade a fase orgânica inibiu em 100\% a germinação das sementes das duas plantas receptoras e em $66 \%$ e $78 \%$ o crescimento da radícula e do hipocótilo da planta $S$. obtusifolia, respectivamente e em $41 \%$ a radícula e em $68 \%$ o hipocótilo da planta $M$. pudica, em concentração única de $0,5 \%$ (Figura 1). O extrato bruto etanólico não apresentou atividade fitotóxica.

$\mathrm{O}$ ácido (E)-cinâmico foi testado nos experimentos de inibição da germinação das sementes e crescimento da radícula e hipocótilo das plantas $S$. obtusifolia e $M$. pudica nas concentrações de $0,02,0,04,0,06,0,08$ e 0,10\%. A concentração de $0,10 \%$ inibiu em $95 \%$ e em $99 \%$ a germinação das sementes de M. pudica e S. obtusifolia, respectivamente. Os demais valores inibitórios em percentuais estão relacionados na Tabela 1 .

$\mathrm{Na}$ Tabela 2, estão relacionados os valores estatísticos de fitotoxicidade do ácido (E)-cinânico sobre as duas plantas testes nas concentrações relacionadas na Tabela 1. Os valores do ceficiente de determinação $\left(\mathrm{R}^{2}\right)$, concentração (\%) tóxica para inibição de $50 \%$ da germinação das sementes ou do crescimento das plântulas $\left(\mathrm{CI}_{50}\right)$ e o limite de confiança a $95 \%$ de probabilidade do $\mathrm{CI}_{50}\left(\mathrm{LC}_{95 \%}\right)$ calculados para a planta $S$. obtusifolia e para a $M$. pudica estão relacionados na Tabela 2. Na Figura 2, estão demonstrados os gráficos de regressão linear da fitotoxicidade versus as concentrações dos tratamentos com o ácido (E)-cinâmico e suas respectivas equações de regressão linear. 
FIGURA 1: Valores inibitórios da germinação de sementes e crescimento de plântulas pela fase orgânica na concentração de $0,5 \%$ em relação ao tratamento testemunha, água destilada.

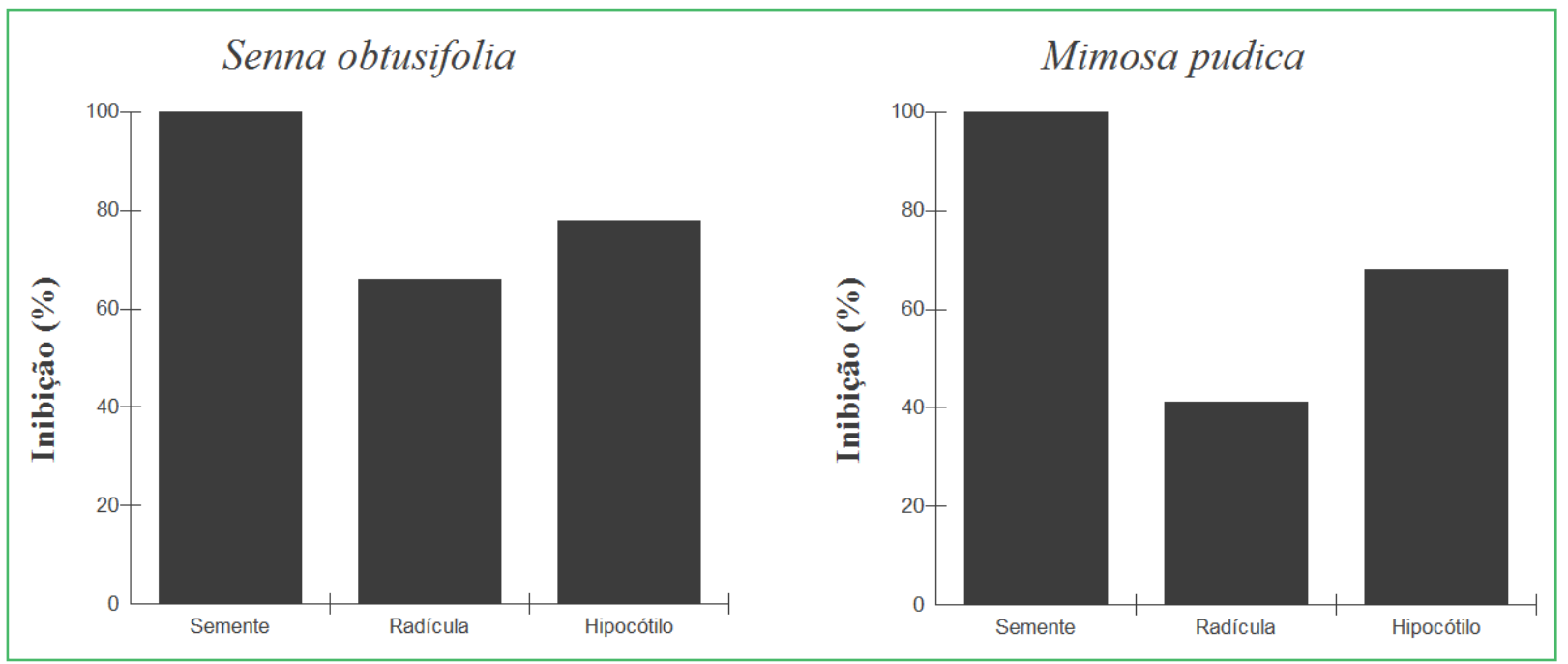

TABELA 1: Percentuais de inibição de germinação de sementes e crescimento de plântulas pelo ácido (E)-cinâmico.

\begin{tabular}{ccccccc}
\hline & \multicolumn{5}{c}{ Valores inibitórios (\%) } \\
\hline$[\%]$ & Serm. obtusifolia & Rad. & Hip. & Germ. & Rad. & Hip. \\
0,02 & $14 \mathrm{ab}$ & $49 \mathrm{~b}$ & $19 \mathrm{ab}$ & $30 \mathrm{~b}$ & $36 \mathrm{ab}$ & $16 \mathrm{ab}$ \\
0,04 & $24 \mathrm{~b}$ & $57 \mathrm{~b}$ & $21 \mathrm{ab}$ & $49 \mathrm{~b}$ & $33 \mathrm{~b}$ & $26 \mathrm{ab}$ \\
0,06 & $45 \mathrm{c}$ & $62 \mathrm{~b}$ & $29 \mathrm{abc}$ & $81 \mathrm{c}$ & $29 \mathrm{~b}$ & $32 \mathrm{ab}$ \\
0,08 & $64 \mathrm{~d}$ & $62 \mathrm{~b}$ & $39 \mathrm{bc}$ & $94 \mathrm{c}$ & $45 \mathrm{~b}$ & $39 \mathrm{~b}$ \\
0,10 & $95 \mathrm{e}$ & $63 \mathrm{~b}$ & $60 \mathrm{c}$ & $99 \mathrm{c}$ & $42 \mathrm{~b}$ & $41 \mathrm{~b}$ \\
CV (\%) & 16,09 & 10,57 & 15,86 & 26,89 & 16,48 & 14,98 \\
\hline
\end{tabular}

Germ. (Inibição da germinação); Rad. (Inibição do crescimento da radícula) e Hip. (Inibição do crescimento do hipocótilo). CV (Coeficiente de variação). As médias seguidas de uma mesma letra não variam estatisticamente pelo teste de Tukey a 5\% de probabilidade.

TABELA 2: Dados de regressão linear com os parâmetros de fitotoxicidade dos tratamentos, utilizando o ácido (E)-cinâmico em diferentes concentrações sobre inibição da germinação de sementes e crescimento de plântulas em relação ao tratamento testemunha, água destilada.

\begin{tabular}{|c|c|c|c|c|c|c|}
\hline & \multicolumn{6}{|c|}{ Valores inibitórios (\%) } \\
\hline & \multicolumn{3}{|c|}{ S. obtusifolia } & \multicolumn{3}{|c|}{ M. pudica } \\
\hline & Germ. & Rad. & Hip. & Germ. & Rad. & Hip. \\
\hline $\mathrm{R}^{2}$ & 0,97 & 0,80 & 0,89 & 0,93 & 0,34 & 0,95 \\
\hline $\mathrm{CI}_{50}$ & 0,063 & 0,009 & 0,091 & 0,037 & $\approx 0,071$ & 0,117 \\
\hline $\mathrm{LC}_{95 \%}$ & 0,06 a 0,07 & 0,01 a 0,03 & 0,08 a 0,10 & 0,04 a 0,05 & ND & 0,11 a 0,13 \\
\hline
\end{tabular}

Germ. (Inibição da germinação); Rad. (Inibição do crescimento da radícula) e Hip. (Inibição do crescimento do hipocótilo). R²: Regressão linear; $\mathrm{CI}_{50}$ : Concentração (\%) tóxica para inibição de 50\% da germinação das sementes ou do crescimento das plântulas; $\mathrm{LC}_{95 \%}$ : limite de confiança a $95 \%$ de probabilidade do $\mathrm{CI}_{50}$; $\mathrm{ND}$ (não determinado). 
FIGURA 2: Gráficos de regressão linear da fitotoxicidade versus as concentrações dos tratamentos com o ácido (E)-cinâmico em relação à germinação das sementes, crescimento da radícula e do hipocótilo das plantas Senna obtusifolia e Mimosa pudica, comparados com a testemunha, água destilada.

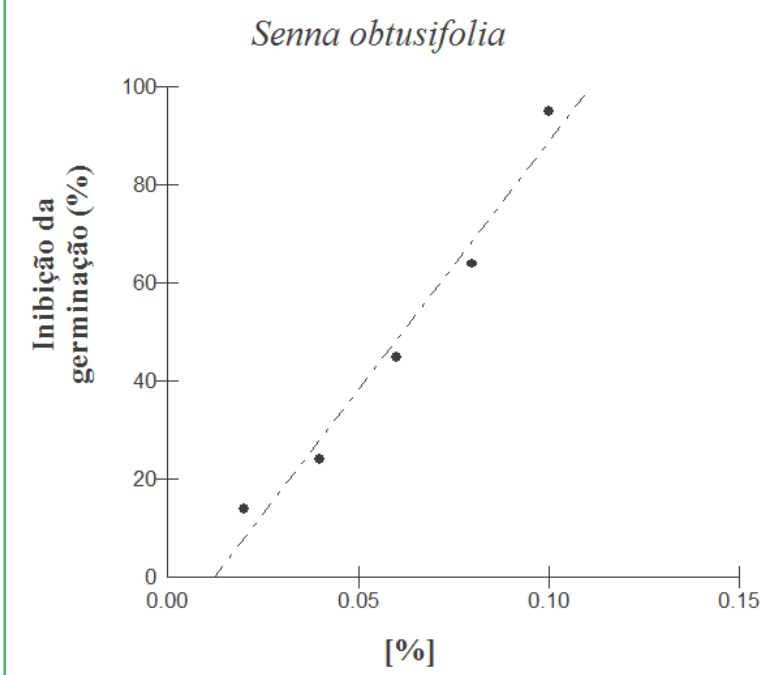

Senna obtusifolia

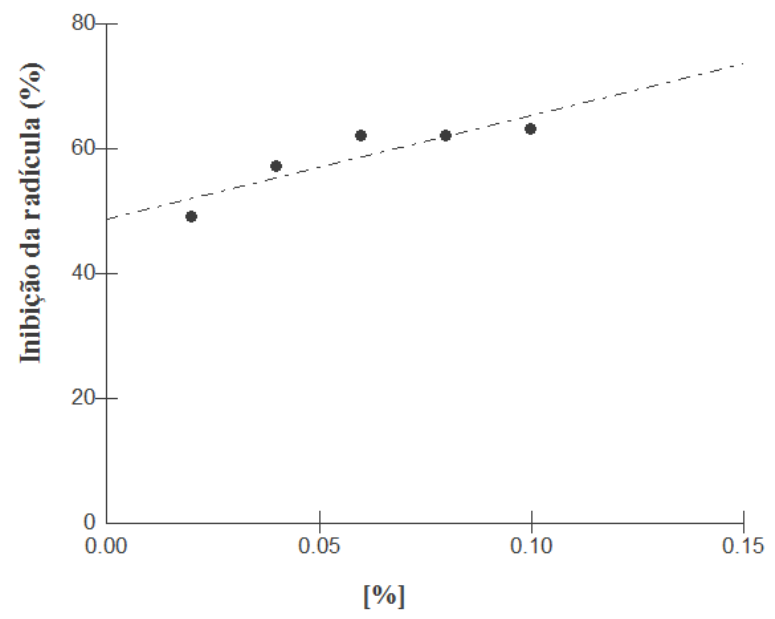

Senna obtusifolia

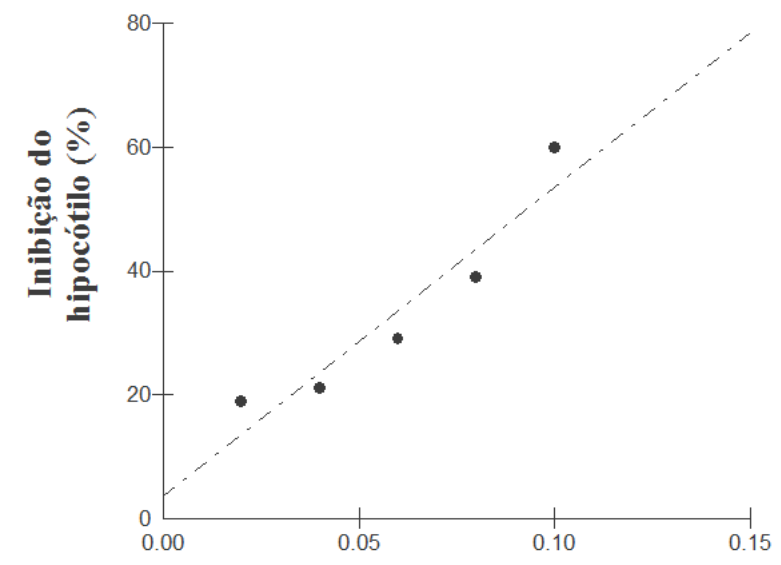

[\%]

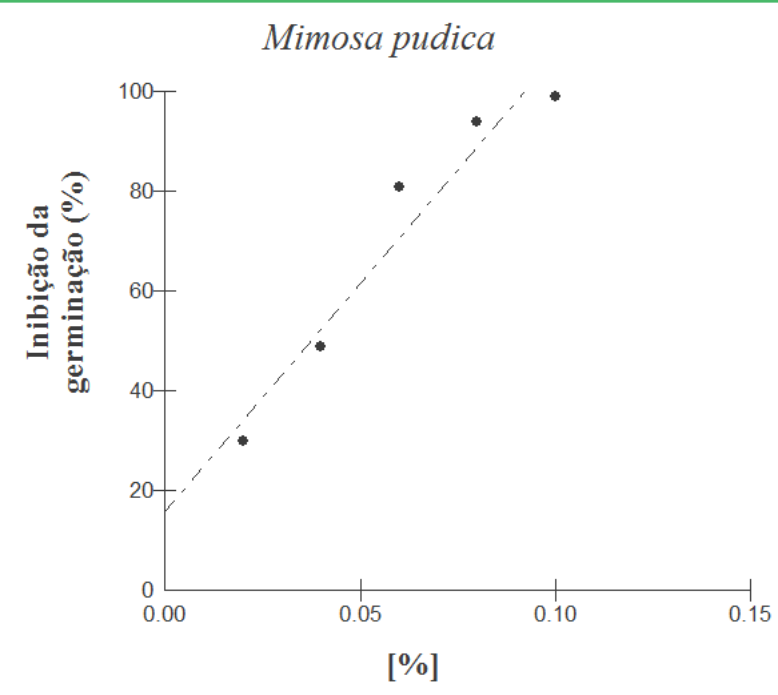

Mimosa pudica

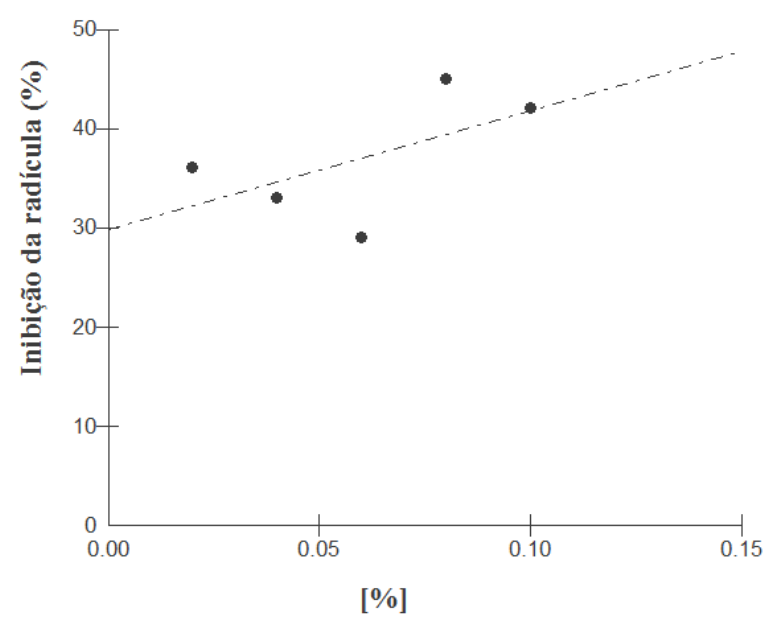

Mimosa pudica

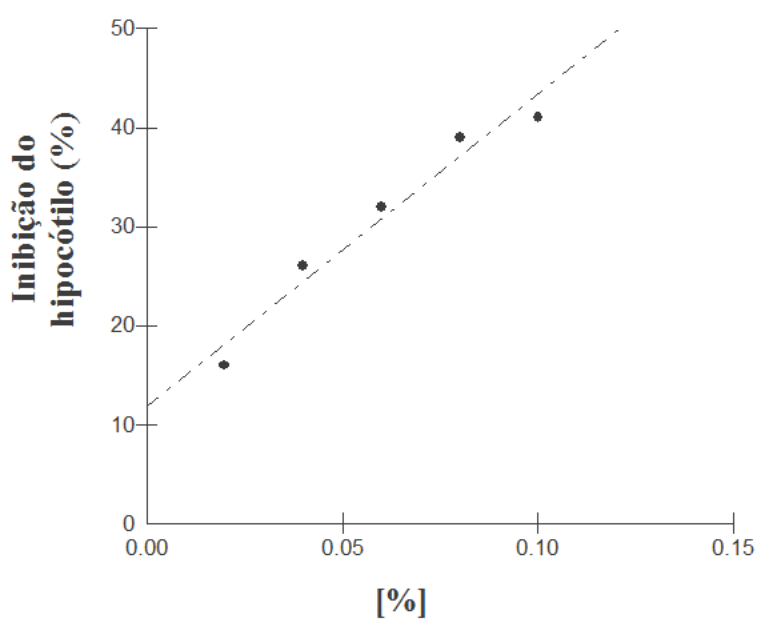




\section{Discussão}

Nesse estudo, a fase orgânica apresentou elevado potencial fitotóxico e foi submetida à investigação química, utilizando-se cromatografia em coluna (CC), cujo composto majoritário obtido foi o ácido (E)cinâmico. Confirmado através da análise dos espectros de massas dos oitos picos principais do íon cromatograma da fase orgânica submetida à técnica CG-EM, o ácido (E)-cinâmico era o composto majoritário com $89,15 \%$ (pico 3, m/z 148) (BARBOSA, 2008; VIEIRA, 2010). A confirmação do ácido (E)-cinâmico se deu pela análise dos espectros de $\mathrm{RMN}{ }^{1} \mathrm{H}$ e de $\mathrm{RMN}{ }^{13} \mathrm{C}$ e está de acordo com a literatura (XIA et al., 2010).

Os efeitos fitotóxicos do extrato bruto $(\mathrm{CETOH})$ e da fase orgânica da espécie C. cujete foram avaliados em ensaios de germinação das sementes das plantas-teste $S$. obtusifolia e $M$. pudica. O extrato bruto $\mathrm{CETOH}$ nas concentrações testadas não apresentou fitotoxicidade. No entanto, a fase orgânica inibiu $1000 \%$ a germinação das sementes das duas plantas receptoras, utilizando concentração de $0,5 \%$. Comparativamente, o óleo de nim (Azadirachta indica A. Juss.) a 3,0\% apresentou $40 \%$ de inibição da germinação das sementes de $S$. obtusifolia e M. pudica (SOUZA FILHO et al., 2009), ou seja, essa concentração é seis vezes maior do que a utilizada para a fase orgânica, e, ainda, duas vezes e meia menos ativa. A fase orgânica também apresentou resultados expressivos na inibição do crescimento da radícula e hipocótilo, inibindo o crescimento da radícula em $66 \%$ e do hipocótilo em $78 \%$ de S. obtusifolia e em $41 \%$ e $68 \%$, para a radícula e hipocótilo de $M$. pudica, respectivamente. Os resultados aqui obtidos também são superiores aos observados na inibição da germinação de sementes e o desenvolvimento da raiz de $M$. pudica e $S$. obtusifolia causada pelos extratos hexânico e etanólico a 1,0\% de três espécies de Copaifera (Copaifera duckei, C. martii e C. reticulata); destaca-se, ainda, que a concentração utilizada no presente trabalho foi de $0,5 \%$, ou seja, a metade da concentração dos extratos de Copaifera (SOUZA FILHO et al., 2010).

O ácido (E)-cinâmico, o composto majoritário da fase CEA foi testado também nos experimentos de inibição da germinação das sementes e crescimento da radícula e hipocótilo das plantas $S$. obtusifolia e $M$. pudica nas concentrações de 0,02, 0,04, 0,06, 0,08 e 0,1\%. Foram observados efeitos inibitórios de $95 \%$ e em $99 \%$ na germinação das sementes de $M$. pudica e $S$. obtusifolia, respectivamente, utilizando a maior concentração.

A Figura 2 apresenta os gráficos de regressão linear, onde o efeito inibitório ocorreu proporcionalmente ao aumento da concentração, considerando todos os tratamentos. Para S. obtusifolia, o coeficiente de determinação $\left(\mathrm{R}^{2}\right)$ foi de 0,97 e $\mathrm{CI}_{50}$ igual a $0,063 \%$ e para $M$. pudica, $\mathrm{R}^{2}$ igual a 0,93 e $\mathrm{CI}_{50}$ de $0,037 \%$ com intervalo de confiança a $95 \%$ de $0,036-0,048 \%$.

Os dados experimentais relatados neste trabalho reforçam as informações apresentados por Souza Filho et al. (2005) que, estudando os efeitos de inibição da germinação de sementes de três plantas invasoras, entre elas $S$. obtusifolia e $M$. pudica pelo ácido $p$-cumárico, também um fenilpropanoide, constataram que aumentando a concentração do ácido $p$-cumárico aumentava também os valores inibitórios. Em relação às plântulas, destacase nos ensaios de fitotoxicidade a inibição de $60 \%$ do crescimento do hipocótilo da planta $S$. obtusifolia na presença de ácido (E)-cinâmico na concentração de $0,10 \%$. A inibição do crescimento da radícula da planta S. obtusifolia foi de $63 \%$ e da M. pudica de $42 \%$.

Considerando-se os dois bioensaios de crescimento de plântulas, a planta $S$. obtusifolia sofreu maior inibição do crescimento em comparação com a $M$. pudica. Os dados experimentais aqui relatados reforçam as informações apresentados por Chon et al. (2002) que demonstram que compostos como a cumarina, o ácido (E)-cinâmico, o ácido o-cumárico reduziram significamente o comprimento de raízes de alfafa (Medicago sativa L.) e capim-arroz (Echinochloa crusgalli, Beauv. var. oryzicola Ohwi).

Observações de danos à raiz em nível celular, evidenciado pelas alterações na morfologia celular e organização interna são relatadas por Hui Li et al. (2010). Corroboram também para essas informações o estudo com a espécie conhecida como Anagallis arvensis, cujos extratos aquosos, de onde foram identificados os ácidos fenólicos, ácido (E)-cinâmico, ácido cafeico e ácido salicílico, inibiram a germinação e crescimento da radícula de seis espécies receptoras (REBAZ et al., 2001). 
Estudos sugerem que a aplicação exógena dos ácidos (E)-cinâmico, $p$-cumárico e ferúlico induzem a prematura cessação do crescimento das raízes de soja e, em nível metabólito, são canalizados dentro da via dos fenilpropanoides e convertidos nos correspondentes alcoóis, seguido por excessiva produção de monolignois, os quais são polimerizados formando lignina, que enrijece a parede vegetal e restringe o crescimento da planta (KAUR et al., 2005; SIMÕES et al., 2010).

Esse é o primeiro relato de estudo de atividade fitotóxica da espécie Crescentia cujete e, também a primeira divulgação da obtenção do ácido (E)cinâmico na polpa dos frutos dessa espécie. As etapas dessa pesquisa reforçam em seus procedimentos a ação fitotóxica do ácido (E)-cinâmico, inicialmente verificada na fase em acetato de etila (CEA), rica nesse fenilpropanoide, como demonstrado nesse trabalho. Os efeitos fitotóxicos evidenciados são condizentes com dados e relatos de estudos alelopáticos dos chamados fenilpropanoides.

Conclui-se que a fase orgânica obtida da polpa dos frutos de $C$. cujete pode ser uma alternativa no controle de plantas invasoras auxiliando a agricultura orgânica, contudo, novos estudos com concentrações menores e estudo e in vivo devem ser realizados, bem como, para o ácido (E)-cinâmico que é o composto majoritário na fase orgânica ativa.

\section{Agradecimentos}

Os autores agradecem a Universidade federal do Pará, ao Centro de Ciências Agrárias e Ambientais da Universidade Federal do Maranhão e a EMBRAPA pelo suporte de infraestrutura e a FAPESPA e FAPEMA pelo suporte financeiro.

\section{Referências}

BARBOSA, D. de A. Avaliação fitoquímica e farmacológica de Genipa americana L. (Rubiaceae). 2008. 115 f. Dissertação (Mestrado em Farmácia) - Universidade Federal do Rio de Janeiro, Rio de Janeiro. 2008.

BRASIL - MINISTÉRIO DA AGRICULTURA. Regras para análise de sementes. Brasília: Departamento Nacional de Produção Vegetal, 2009. 365 p.
CHON, S.-U.; CHOI, S.-K.; JUNG, S.; JANG, H.-G.; PYO, B.-S.; KIN, S.-M. Effects of alfalfa leaf extracts and phenolic allelochemicals on early seedling growth and root morphology of alfalfa and barnyard grass. Crop Protection, Guildford, v. 21, n. 10, p. 1077-1082, 2002.

DAYAN, F. E.; DUKE, S. O. Natural compounds as next generation herbicides. Plant Physiology, Mississipi, v. 166, n. 3, p. 10901105, 2014.

GOUVEIA, V. L. M. Avaliação do potencial farmacológico de metabólitos secundários de Cystoseira abies-marina. $2012.94 \mathrm{f}$. Dissertação (Mestrado em Ciências Biomédicas). Departamento de Ciências Tecnológicas e Desenvolvimento, Universidade dos Açores - Ponta Delgada (Portugal). 2012.

HELTZEL, C. E.; GUNATILAKA, A. A. L.; GLASS, T. E.; KINGSTON, D. G. I. Bioactive furanonaphthoquinones from Crescentia cujete. Journal of Natural Products, Columbus, v. 56, n. 9 , p. $1500-1505,1993$.

HUI LI, Z.; WANG, Q.; RUAN, X.; PAN, C.-DE; JIANG, D.-A. Phenolics and Plant Allelopathy. Molecules, Basel, v. 15, p. 89338952,2010

INDERJIT; DAKSHINI, K. M. M. On laboratory biossays in allelopathy. The Botanical Review, New York, v. 6, n. 1, p. 28-44, 1995.

KANEKO, T.; OHTANI, K.; KASAI, R.; YAMASAKI, K.; DUC, N. M. Iridoids and iridoid glucosides from fruits of Crescentia cujete. Phitochemistry, Leiden, v. 46, n. 5, p. 907-910, 1997.

KANEKO, T.; OHTANI, K.; KASAI, R.; YAMASAKI, K.; DUC, N. M. n-Alkyl glycosides and p-hidroxybenzoyloxy glucose from fruits of Crescentia cujete. Phitochemistry, Leiden, v. 47, n. 2, p. 259-263, 1998.

KAUR, H.; INDERJIT; KAUSHIK, S. Cellular evidence of allelopathic interference of benzoic acid to mustard (Brassica juncea L.) seedling growth. Plant Physiology and Biochemistry, Versailles, v. 43, n. 1, p. 77-81, 2005.

MACÍAS, F. A.; CASTELLANO, D.; MOLINILLO, J. M. G. Search for a standard phytotoxic bioassay for allelochemicals. Selection of standard target species. Journal of Agricultural Food and Chemistry, Washington, v. 48, n. 6, p. 2512-2521, 2000.

MACÍAS, F. A.; GALINDO, J. L. G.; GALINDO, J. C. G. Evolution and current status of ecological phytochemistry. Phytochemistry, Leiden, v. 68, n. 22-24, p. 2917-2936, 2007.

NOVAES, P.; IMATOMI, M.; MIRANDA, M. A. F. M.; GUALTIERI, S. C. J. Phytotoxicity of leaf aqueous extracts of Rapanea umbellata (Mart.) Mez (Primulaceae) on weeds. Acta Scientiarum. Agronomy, Maringá, v. 35, n. 2, p. 231-239, 2013.

REBAZ, Z.; SHAUKAT, S. S.; SIDDIQUI, I. A. Allelopathic potencial of Anagallis arvensis L.: A cosmopolitan weed. Pakistan Journal of Biological Sciences, Faisalabad, v. 4, n. 4, p. 446-450, 2001.

SANTOS, L. S.; BORGES, F. C.; OLIVEIRA, M. N.; FERREIRA, I. C. S.; GUILHON, G. M. S. P.; SOUZA FILHO, A. P. S.; SANTOS, A. S.. ARRUDA, M. S. P.; MÜLLER, A. H. and ARRUDA, A. C. Allelochemicals isolated from the leaves of Virola michelli Heckel. Allelopathy Journal, Haryana, v. 20, p. 235-241, 2007.

SILVA, P. S. S. da. Atuação dos aleloquímicos no organismo vegetal e formas de utilização da alelopatia na agronomia. Biotemas, Florianópolis, v. 25, n. 3, p. 65-74, 2012. 
SIMÕES, C. M. O.; SCHENKEL, E. P.; GOSMANN, G.; MELLO, J. C. P de; MENTZ, L. A.; PETROVICK, P. R. Farmacognosia: da planta ao medicamento. 6. Ed. Porto Alegre, Editora da UFRGS; Florianópolis: Editora da UFSC, 2010. 1104 p.

SOUZA FILHO, A. P. S.; PEREIRA, A. A. G.; BAYMA, J. C. Aleloquímico produzido pela gramínea forrageira Brachiaria humidicola. Planta Daninha, Viçosa, v. 23, n. 1, p. 25-32, 2005.

SOUZA FILHO, A. P. S.; CUNHA, R. L.; VASCONCELOS, M. A. M. de. Efeito inibitório do óleo de Azadirachta indica A. Juss. Sobre plantas daninhas. Revista Ciências Agrárias, Belém, n. 52, p. 79-86, 2009.

SOUZA FILHO, A. P. S.; GURGEL, E. S. C.; QUEIROZ, M. S. M.; SANTOS, J. U. M. Atividade alelopática de extratos brutos de três espécies de Copaifera (Leguminosae-Caesal pinioideae). Planta Daninha, Viçosa, v. 28, n. 4, p. 743-751, 2010.

SOUZA, V. C.; LORENZI, H. Botânica sistemática: Guia ilustrativo para identificação das famílias de angiospermas da flora brasileira, baseado em APG II, São Paulo, Nova Odessa, SP, 2005, 155 p.
TESIO, F.; WESTON, L. A.; FERRERO, A. Allelochemicals identified from Jerusalem artichoke (Helianthus tuberosus L.) residues and their potential inhibitory activity in the field and laboratory. Scientia Horticulturae, Amsterdam, v. 129, n. 3, p. 361-368, 2011.

VIEIRA, M. G. S. Estudo químico de Xylopia nitida Dunal (Annonaceae). 2010. 170 f. Dissertação (Mestrado em Química Orgânica) - Universidade Federal do Ceará, Fortaleza. 2010.

WANG, W. Root elongation method for toxicity testing of organic and inorganic pollutants. Environmental Toxicology \& Chemistry, Porto, v. 6, p. 409-414, 1987.

WANG, G.; YIN, W.; ZHOU, Z.-Y.; HSIEH, K.-L.; LIU, J.-K. New iridoides from the fruits of Crescentia cujete. Journal of Asian Natural Product Research, London, v. 12, n. 9, p. 770-775, 2010. XIA, L.-Z.; ZHOU M.; XIAO Y.-H.; LI G.-Y.; XIAO-ZHEN; ZHANG G.-L. Chemical constituents from Helwingia japonica. Chinese Journal of Natural Medicines, Nanquim, v. 8, n. 1, p. 8933-8952, 2010. 